\title{
Meeting you was a fake: Investigating the increase in romance fraud during COVID-19
}

DOI:

https://doi.org/10.1108/JFC-02-2021-0042

\section{Document Version}

Accepted author manuscript

Link to publication record in Manchester Research Explorer

\section{Citation for published version (APA):}

Buil-Gil, D., \& Zeng, Y. (2021). Meeting you was a fake: Investigating the increase in romance fraud during COVID19. Journal of Financial Crime. https://doi.org/10.1108/JFC-02-2021-0042

\section{Published in:}

Journal of Financial Crime

\section{Citing this paper}

Please note that where the full-text provided on Manchester Research Explorer is the Author Accepted Manuscript or Proof version this may differ from the final Published version. If citing, it is advised that you check and use the publisher's definitive version.

\section{General rights}

Copyright and moral rights for the publications made accessible in the Research Explorer are retained by the authors and/or other copyright owners and it is a condition of accessing publications that users recognise and abide by the legal requirements associated with these rights.

\section{Takedown policy}

If you believe that this document breaches copyright please refer to the University of Manchester's Takedown Procedures [http://man.ac.uk/04Y6Bo] or contact uml.scholarlycommunications@manchester.ac.uk providing relevant details, so we can investigate your claim.

\section{OPEN ACCESS}




\title{
Meeting you was a fake: Investigating the increase in romance fraud during COVID-19
}

\author{
David Buil-Gil and Yongyu Zeng \\ Department of Criminology, University of Manchester, UK
}

\section{Corresponding author}

David Buil-Gil. G18 Humanities Bridgeford Street Building, Cathie Marsh Institute for Social Research, University of Manchester. E-mail address: david.builgil@manchester.ac.uk

\section{Abstract}

Purpose: Romance fraud refers to situations where an individual is deceived for financial gain by someone with whom the victim perceives to be in a romantic relationship. With the increase in internet use, the growth in loneliness, and the increasing engagement in online dating sites during COVID-19, opportunities for romance fraud may have suffered an important increase. This paper analyses changes in romance fraud, loneliness, and internet use during the pandemic.

Design/methodology: Data about romance fraud reported to the police in the UK, and survey data recorded by the Understanding Society longitudinal survey, are used to address our research questions. Auto Regressive Integrated Moving Average (ARIMA) modelling is used to analyse whether temporal changes observed are an effect of social changes associated with lockdown and stay-athome orders.

Findings: Our analysis shows that cyber-enabled romance fraud experienced a large increase after April 2020 which is greatly above any expected crime variation considering known pre-COVID trends. The increase in romance fraud was more abrupt among young adults than older persons. Our results also indicate that only young adults experienced a significant increase in loneliness, while older adults reported a large increase in internet use during COVID.

Originality: This is a first-of-its-kind article analysing the effect of rapid social changes on a growing type of cyber-enabled fraud. It is likely that the growth in romance fraud during COVID is due to a combined effect of an increase in internet use and growing loneliness rates experienced by many people during the pandemic.

\section{Keywords}

Coronavirus; cybercrime; dating fraud; loneliness; lockdown

\section{Citation}

Buil-Gil, D., and Zeng, Y. (2021). Meeting you was a fake: Investigating the increase in romance fraud during COVID-19. Journal of Financial Crime. https://doi.org/10.1108/JFC-02-2021-0042 


\section{Introduction}

Many have noted that isolation and loneliness experienced by certain population groups increased during COVID-19 due to the far-reaching lockdown and social distancing orders imposed by governments to control the spread of the virus (Hwang et al., 2020; Killgore et al., 2020; Li and Wang, 2020; Loades et al., 2020), but far less have considered how the solitude and sadness suffered by many was exploited by criminals for financial profit. As a consequence of the growth of loneliness and lack of socialisation during the long-lasting pandemic, the internet and social media became the main sources of social interaction for thousands (Király et al., 2020), either as a means for basic connections with friends and family or as a way to meet new people, and maybe even to foster romantic relationships. Dating websites reported record numbers in online engagement during COVID-19 (Chin and Robison, 2020; Goldstein and Flicker, 2020), and many users were experiencing social isolation and vulnerability due to stay-at-home orders, which became the ideal combination of factors for an extensive rise in romance fraud (CIFAS, 2020).

In simple terms, romance fraud refers to situations where an individual is deceived for financial gain by someone with whom the victim perceives to be in a romantic relationship (Buchanan and Whitty, 2014; Cross et al., 2018). The UK Home Office Counting Rules for Recorded Crime consider that dating fraud exists when "the intended victim is befriended on the internet and eventually convinced to assist their new love financially by sending them money for a variety of emotive reasons" (Home Office, 2020: 19). Romance fraud can also be called 'dating fraud' or 'relationship fraud' in some legal texts. This type of fraud is mostly committed through online contexts such as dating apps and websites, social media, and email, but in some cases it can also take place offline. To better understand the dynamics of romance fraud, Whitty (2013) conducted a series of semi-structured interviews with twenty victims and identified the main stages of the 'crime script', which she named the 'Scammers Persuasive Technique Model':

1) a potential victim is motivated to find his or her ideal partner;

2) the same person is presented with the ideal profile (e.g., physically attractive person, in a professional job in the case of fake male profiles, or in a low-paying job in the case of fake female profiles) usually through an online dating platform or social media;

3 ) the grooming process occurs, where the fraudster gains the victims' confidence and trust;

4) the 'string' (i.e., the criminal initiates the first requests for money, usually small quantities);

5) the scam continues and the fraudster continues asking for small amounts of money, sometimes over long periods of time;

6) sexual abuse (i.e., when victims reveal they have no money left, the offender hypes up the sexual connection and asks the victim to take off his or her clothes in front of a webcam, which may later be used as blackmail to request a ransom payoff); and

7) 're-victimisation', which can take several forms (e.g., the offender accepts the scam but tells the victim that during the fraud process he or she felt genuinely in love, a 'new' romantic relationship with another scammer begins, or the same scammer impersonates a law enforcement agency and asks for money to fund the investigation).

Romance fraud is known to have devastating psychological effects on victims (i.e., increase in stress and anxiety, and in some cases depression), in addition to the severe financial effects (Carter, 2020; Cross et al., 2018). Since fraudsters often reside in separate jurisdictions, investigating and prosecuting romance fraud has been a challenge for law enforcement agencies, and victims rarely recover the financial losses (Buchanan and Grant, 2001). Moreover, while loneliness is known to be a major risk factor for romance fraud victimisation, suffering such a crime may further increase victims' social isolation and in turn their vulnerability to be re-victimised. 
While several official sources in the UK have indicated an increase in romance fraud since March 2020 (Action Fraud, 2020; Garside, 2020), to our knowledge no one has yet presented an evaluation of the extent of such an increase, and whether changes in romance fraud can be attributed to COVID-related stay-at-home orders or such an increase is simply a continuation of an upward trend observed before COVID. This paper presents preliminary analyses to examine the growth of romance fraud during COVID-19. Data recorded by Action Fraud, the UK fraud and cybercrime reporting centre, are analysed to assess temporal changes in romance fraud, while analyses of data recorded in the Understanding Society longitudinal survey (Institute for Social and Economic Research, 2020, 2021) are used to explore changes in loneliness and internet use during the same period. Our preliminary results indicate a statistically significant increase in romance fraud during COVID, which is likely to be associated with an increase in loneliness amongst young adults and a generalised increase in internet use among older adults.

The remainder of the paper is structured as follows: Section 2 presents a review of the literature about the effect of social distancing orders on loneliness and crime. Section 3 discusses our methodology. Section 4 presents an analysis of changes in romance fraud during COVID, and examines changes in internet use and loneliness. Finally, Section 5 presents the discussion, conclusions, and limitations of our study.

\section{Social distancing, loneliness, and online fraud}

Criminologists all around the globe have reported important changes in crime during COVID-19. With lockdown and social distancing restrictions being imposed at the national and local levels to control the spread of the virus, social dynamics and the use of public spaces experienced unprecedented changes which had clear effects on crime rates. To mention a few examples, Mohler et al. (2020) analysed crime data in Los Angeles and Indianapolis, in the United States, and reported that residential burglary decreased during COVID due to households being occupied by residents during day and night, while domestic violence increased because potential offenders and victims were confined together over extended periods of time. Abrams (2021) analysed data from 25 large cities in the United States and showed a drop in crime incidents and arrests related to drug crime, theft, residential burglary, and some types of violent crime, while homicides and shootings did not decrease, and non-residential burglary increased. Piquero et al. (2020) also reported a short-time spike in domestic violence in Dallas. Changes in crime trends, nonetheless, have been seen to differ across communities and crime types (Campedelli et al., 2020; Langton et al., 2021).

One of the crime types that may have benefitted the most from the pandemic and lockdown measures is cybercrime and online fraud. With people spending more time at home, and connected to the internet for homeworking, online shopping, and leisure, opportunities for online crime increased rapidly. In this regard, growing research interest is being directed to explore the increase in cybercrime during COVID. Building on Routine Activity Theory (Cohen and Felson, 1979), one may expect that the generalised increased in internet use contributed to an increase in opportunities for offenders to converge with likely targets (in the absence of capable guardians) through online contexts. Buil-Gil et al. (2020) analysed data about crimes reported to UK Action Fraud and observed a short-term increase in online shopping fraud and hacking of social media and email, which are the two most common cybercrime categories in the UK. They also noted that while the increase in reports of online shopping fraud impacted both individuals and businesses, the increase in cyber-dependent crime (i.e., those offences that can only be committed using Information and Communications Technology devices) was mainly associated with reports from individual victims rather than organisations. Payne (2020) analysed data from the US Federal Trade Commission and reported a short-term increase in frauds 
connected to the internet (e.g., imposter business, fraudulent text messages). This study also noted that reports of romance fraud increased in the first three months of 2020 in comparison with the same period in 2019, and this increase was experienced by all age groups. Kemp et al. (2021) used data about crimes known to UK authorities between April 2019 and July 2020 and observed a statistically significant increase in online shopping fraud, romance fraud, and cyber-dependent crime, and a significant decrease in ticket fraud. Finally, Cross (2020) argued that even though there is a lack of data to analyse the impact of COVID on fraud, government restrictions on social interactions may have increased older persons' vulnerability to fraud, including romance fraud. In this paper we present the results of a first-of-its kind study analysing the effect of COVID on romance fraud records.

Collier et al. (2020) also observed significant uplifts in denial-of-service attacks and online frauds globally, and argued that cybercriminals were adapting their strategies to exploit the psychological effects of the pandemic (e.g., worry about the virus and greater public demand for security). They also argued that it was likely that offenders were abusing the vulnerability of persons who felt lonely during COVID, who spent more time connected to the internet, to commit romance scam and 'eWhoring' (i.e., when online sexual encounters are simulated for financial gain). This is indeed not surprising, since previous research had already noted that isolation and loneliness may be key factors associated with online dating and romance fraud victimisation. Lawson and Leck (2006), for instance, argued that loneliness is one of the most important factors motivating people to search for partners online, and Al-Saggaf and Nielsen (2014) observed that female Facebook users who feel lonely tend to disclose personal information more often than those with strong social bonds. Cross (2016) interviewed twenty-one volunteers who provide support to senior citizens who have suffered fraud in Canada, and reported that loneliness was perceived to be associated with romance fraud in two different ways: first, it provides the motivation for potential victims to engage in online dating, and second, it provides the means through which fraudsters establish the relationship and gain the victims' confidence. Nonetheless, Buchanan and Whitty (2014) analysed UK survey data and found that the association between loneliness and romance fraud victimisation was not statistically significant, while romantic beliefs were an important predictor of suffering this type of fraud. Loneliness, however, was associated with emotional distress among non-financial victims of romance fraud. Other predictors that have been previously associated with romance fraud victimisation are gender (females are more commonly victimised than males), age (middle-age people tend to suffer this crime more often than younger or older adults), and traits such as sensation seeking, urgency, and kindness (Whitty, 2018).

Given that COVID-related lockdown and social distancing policies may have worsened the loneliness and social isolation suffered by many (Hwang et al., 2020; Killgore et al., 2020; Loades et al., 2020), especially younger adults ( $\mathrm{Li}$ and Wang, 2020), and as a consequence dating sites have seen a large increase in engagement (Chin and Robison, 2020; Goldstein and Flicker, 2020), it is also likely that romance fraud has grown significantly.

\subsection{Research questions}

Based on the literature review presented above, we devise the following research questions that will be addressed using police and survey data recorded in the UK:

1. Did romance fraud experience a significant increase during COVID-19?

2. Were all population groups equally affected by temporal changes in romance fraud during COVID-19?

3. Did loneliness and internet use, which are key predictors of romance fraud victimisation, experience significant changes during COVID-19? 


\section{Methodology}

In order to address our research questions and explore changes in romance fraud during COVID, we analyse data recorded from two different sources: reports of romance fraud known to Action Fraud between April 2014 and December 2020, and estimates of loneliness and internet use recorded by the Understanding Society longitudinal survey between January 2017 and November 2020 (Institute for Social and Economic Research, 2020, 2021).

Data on romance fraud reports were obtained through a freedom of information request to the City of London Police, which is responsible for running Action Fraud alongside the UK National Fraud Intelligence Bureau. We received data about the total number of frauds known to the police every month between April 2014 and December 2020, which will be used to analyse changes in trends before and during the pandemic. Moreover, the Action Fraud data dashboard (https://www.actionfraud.police.uk/data) publishes information about the personal characteristics of victims (e.g., age, gender, if victims are individuals or organisations), whether crimes are reported via telephone or website, and whether victims require special support from the police, among other variables, for the last 13 months. These data will be used to obtain further insights about groups of victims affected by this type of fraud. More specifically, since we only obtained access to this detailed information for months between November 2019 and December 2020, we will analyse differences in crime by population groups in November-December 2019 (i.e., before the pandemic) and NovemberDecember 2020 (i.e., during the pandemic, which coincides with the second UK national lockdown in November and strict 'tier four' restrictions in high-COVID-density areas in December).

In order to explore changes in loneliness and internet use during the pandemic, which may be related to a potential increase in online romance fraud, we use longitudinal data recorded by the Understanding Society survey. Understanding Society, which is also known as the UK Household Longitudinal Study, is a longitudinal survey of approximately 40 thousand households in the UK. At wave 1 (2009-2011), households were recruited and asked information about the health, work, education, income, and social life of their members. It is a longitudinal survey, which means that households are visited each year to collect new information on changes in their household, personal circumstances, and social attitudes (Institute for Social and Economic Research, 2020). Interviews used to be carried out face-to-face in respondents' homes or through self-completion online questionnaires, but the COVID waves were fully implemented through web questionnaires. Respondents are aged 16 or over. In this paper we analyse data from waves 9 (2017-2019), 10 (2018-2020), and the first year of wave 11 (2019), as well as waves 1 (April 2020), 2 (May 2020), 3 (June 2020), 4 (July 2020), 5 (September 2020), and 6 (November 2020) of the COVID-19 editions of this same survey. As discussed by survey administrations, the COVID-19 waves are designed to allow linking data from this survey to respondents in previous and future waves (Institute for Social and Economic Research, 2021). At least 1,685 respondents were sampled each month since January 2017, with an average of 4,166 respondents monthly. The sample size in the six COVID-19 waves was increased to improve the reliability of monthly estimates used for temporal comparisons (i.e., 17,761 in wave 1, 14,811 in wave $2,14,123$ in wave $3,13,754$ in wave $4,12,876$ in wave 5 , and 12,035 in wave 6 ).

More specifically, we analyse the proportion of respondents who answer 'some of the time' or 'often' to the question 'how often did you feel lonely?' every month (i.e., as an indicator of loneliness), and the proportion of respondents who use the internet daily (i.e., those who answer 'every day' in the pre-COVID waves, or 'almost all of the time', 'several times a day' or 'once or twice a day' in the COVID waves, to the question 'How often do you use the internet for your personal use?') to measure changes in internet use. We note that the question about internet use was only included in the wave 5 of the COVID-19 survey (September 2020), and thus we can only compare pre-COVID internet usage 
with internet use in September 2020. Nonetheless, there is extensive research suggesting that loneliness is a multidimensional construct driven by multiple indicators of social support, happiness, exclusion, personal tolerance to being alone, and others (e.g., Russell et al., 1978), and the 20-item UCLA scale of loneliness should be used where possible. While some pre-COVID waves of the Understanding Society survey included more specific measures of loneliness, the COVID waves only included a single measure of frequency of loneliness feelings, and thus we can only analyse loneliness from a single-dimensional construct in this research. Future research should utilise the UCLA scale of loneliness where possible. On average, after merging all waves of the survey, $36.7 \%$ of respondents feel lonely often or some of the time $(S D=0.48)$, and $79.7 \%$ of respondents use the internet daily (SD $=0.40$ ). These numbers hide important differences across age groups, which will be analysed below.

In order to analyse temporal changes in romance fraud, loneliness, and internet use we use a two-fold strategy adjusted to the data available. First, we estimate univariate Auto Regressive Integrated Moving Average (henceforth, ARIMA) models from the count of crimes known to Action Fraud and the monthly average values of loneliness and internet use obtained from the Understanding Society survey. ARIMA modelling is a widely used method for temporal data analysis which uses past observations of a variable to predict its own values in the future (Hyndman and Athanasopoulos, 2018). More specifically, we first selected observed values of fraud, loneliness, and internet use for all months up until March 2020, when the first COVID lockdown was announced in the UK, and used this information to estimate univariate ARIMA models for each outcome. To estimate ARIMA models of loneliness and internet use, the time period used covered January 2017 to December 2019, since we do not have data for January, February and March 2020. Parameters obtained from ARIMA models were then used to computer 95\% prediction intervals for both the pre-COVID and COVID periods. This allows comparing known values of romance fraud, loneliness, and internet use during COVID with the 95\% prediction intervals computed from known pre-COVID trends, and thus we can identify whether values observed during COVID fall within or without these prediction intervals. If measures observed during COVID are within the $95 \%$ prediction intervals, then we can argue that there is not enough evidence to show that temporal changes are outside the expected variation given by pre-COVID trends, while values outside the $95 \%$ prediction interval would indicate that temporal changes cannot be explained by pre-COVID trends. ARIMA modelling has been previously applied to analyse the effect of COVID on crime in different contexts (e.g., Kemp et al., 2021; Langton et al., 2021; Piquero et al., 2020).

The accuracy of predictions computed from ARIMA models is partly dependent on the quality of the data being used, but it also depends on three parameters used to adjust the model to the structure of our temporal data. These three parameters are the ' $p$ ' (i.e., number of lag observations included in the model), ' $d$ ' (i.e., number of times that observations are differenced, or degree of differencing), and ' $q$ ' (i.e., the order of the moving average). In this paper we use a variation of the HyndmanKhandakar algorithm ${ }^{1}$ to automate the selection of these three components in each of our models (Hyndman and Khandakar, 2008). We follow this procedure to select the model with the best goodness-of-fit indicator for each outcome, thus improving the accuracy of forecasts computed from ARIMA models.

Moreover, in order to obtain further information about potential groups of victims affected by romance fraud, we compare crime data recorded in November-December 2019 and November-

\footnotetext{
${ }^{1}$ The Hyndman-Khandakar algorithm follows a stepwise selection search procedure to choose the model with the lowest possible AICc, which is a bias-corrected version of the Akaike Information Criterion (AIC) for small samples, in each model estimated.
} 
December 2020, and make use of Poisson Mean Tests to analyse whether differences observed between both time periods are statistically significant at a $95 \%$ confidence level.

All analyses were conducted in R software ( $R$ Core Team, 2020) with the assistance of the 'forecast' package (Hyndman and Khandakar, 2008).

\section{Results}

Research results are described in this section: Subsection 4.1 shows changes in romance fraud and aims to answer our first research question, Subsection 4.2 explores whether all population groups were equally affected by the increase in romance fraud, and thus answers our second research question, and Subsection 4.3 explores changes in loneliness and internet use and provides an answer to our third research question.

\subsection{The increase in romance fraud}

Figure 1 shows the count of romance fraud reports visualised by months between 2014 and 2020. As can be seen, reports of romance fraud show a clear upward trend since 2014, but these suffered a very large increase after March and April 2020, which appears to coincide with the COVID-19 pandemic (Kemp et al., 2021). However, further analyses are needed to disentangle whether the observed increase in romance fraud can be attributed to COVID or is simply a continuation of the upward trend observed in previous years. We use more advanced ARIMA modelling to explore whether changes in romance fraud are outside the expected temporal variation seen before COVID.

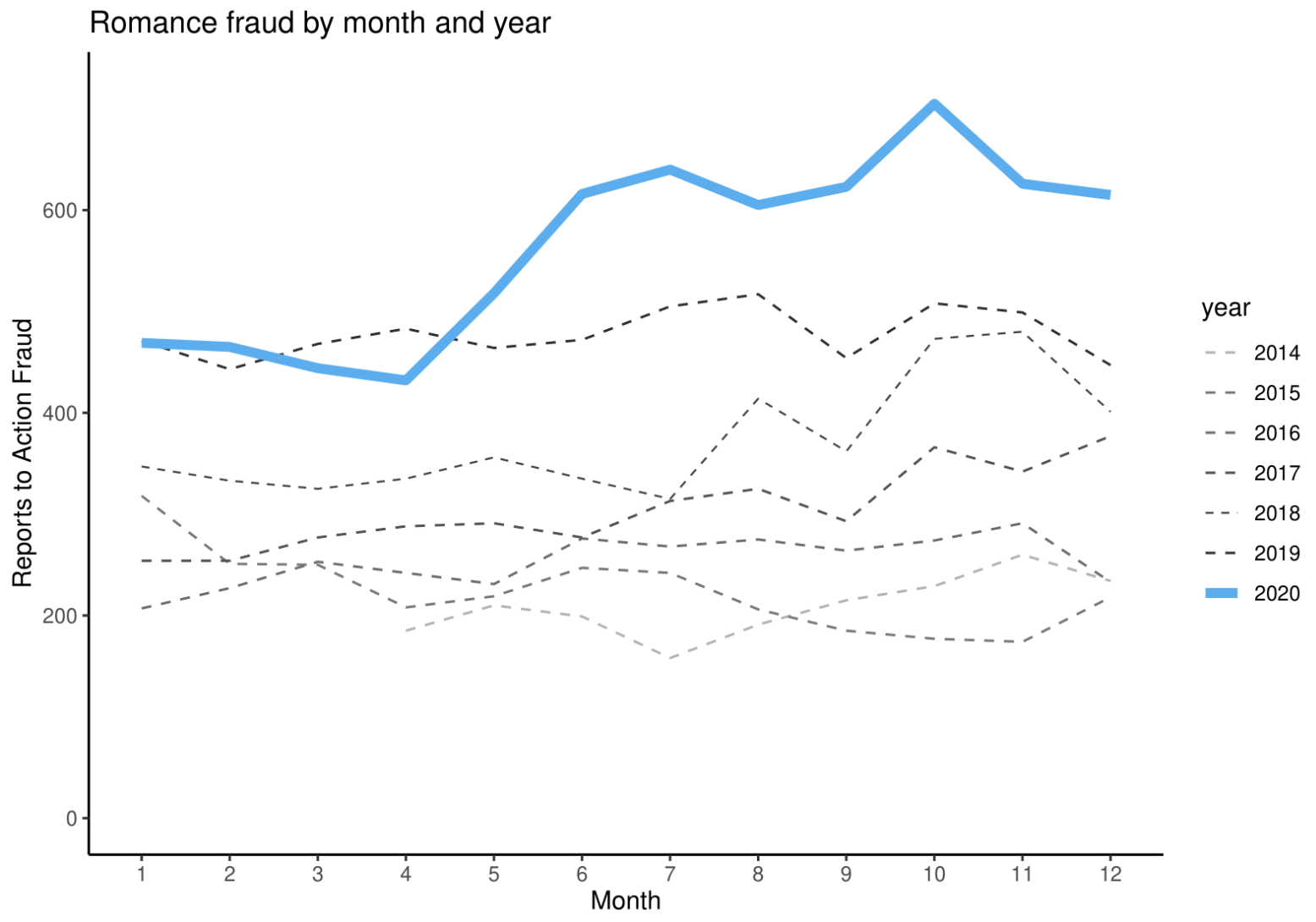

Figure 1. Reports of romance fraud known to Action Fraud by month and year

In Figure 2, we visualise the monthly count of romance fraud between April 2014 and December 2020 and the $95 \%$ prediction intervals computed using ARIMA modelling. First, we can see that our prediction intervals adjust very well to the trend observed between April 2014 and April 2020. Except 
for two very minor exceptions in January 2015 and October 2018, when unexpected increases in fraud were also registered, the line drawn from crime counts always falls within the ARIMA 95\% prediction intervals. This is a good indicator that our ARIMA forecasts have an adequate level of accuracy. We can also see that the number of crimes known to Action Fraud peaked after March 2020 and remained above the upper prediction interval limit since then. In other words, the observed increase in romance fraud seen during the pandemic could not have been predicted from known pre-COVID trends. Thus, in response to our first research question, we observe that romance fraud experienced a significant increase during COVID-19 which is likely to be due to changes provoked by the pandemic.

\section{Romance fraud and $95 \%$ Prediction Intervals}

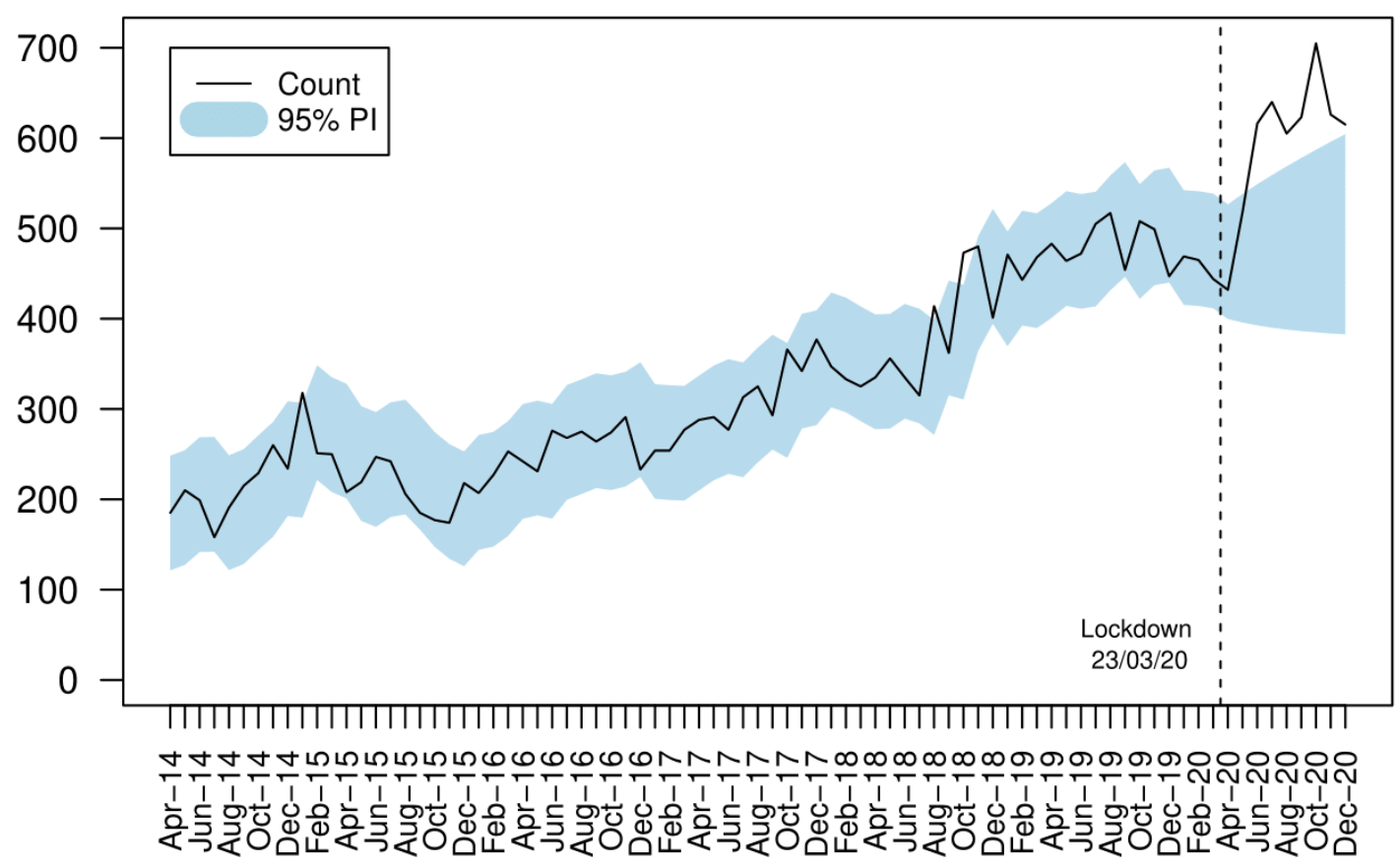

Figure 2. Romance fraud and 95\% prediction intervals

\subsection{Changes in romance fraud suffered by different population groups}

It is likely that temporal changes seen above hide important heterogeneity between groups of victims. Results presented do not allow understanding whether some population groups were more affected by the increase in romance fraud that others. In order to obtain further insights into how the increase in romance fraud affected different groups of victims, and to provide an answer to our research question 2, Table 1 describes crimes registered in November-December 2019 and NovemberDecember 2020, and presents the percentage Relative Difference between both values and whether such difference is statistically significant. Results are presented by the age and gender of victims, reporting channel, and whether victims requested additional support to the police.

In Table 1, we can see that all age groups reported an increase in romance fraud in November and December 2020, and this increase was larger than $10 \%$ in all cases. However, the increase in romance fraud was much more evident among young adults, especially those aged 20 to 29 and 30 to 39, than among older adults. Moreover, the increase seen among victims aged 60 years old or more is not statistically significant. We also see, however, that both before and during COVID, the age groups that 
are more commonly victimised are those aged 40 to 49 and 50 to 59 . In terms of gender, while females reported more romance fraud than males both before and during COVID, the increase in fraud in 2020 seems to be more abrupt among males. We also note that during COVID the number of victims reporting through telephone decreased, while online reporting increased, and the number of victims requiring support from the police increased. As expected, the increase in the overall number of reports of romance fraud is large and statistically significant.

Thus, in answer to our second research question, we observe that while all age groups and genders experienced an increase in romance fraud in November-December 2020, such an increase was only significant among young adults, and the increase seen by male victims was more abrupt than that affecting female victims.

\begin{tabular}{|c|c|c|c|}
\hline & Nov-Dec 2019 & Nov-Dec 2020 & Relative Difference (\%) \\
\hline \multicolumn{4}{|l|}{ Age of victim } \\
\hline 0 to 19 & 27 & 37 & 37.04 \\
\hline 20 to 29 & 100 & 177 & $77.00 * * *$ \\
\hline 30 to 39 & 138 & 199 & $44.21 * *$ \\
\hline 40 to 49 & 188 & 237 & $26.06 * *$ \\
\hline 50 to 59 & 218 & 262 & $20.18^{*}$ \\
\hline 60 to 69 & 155 & 176 & 13.55 \\
\hline 70 to 79 & 91 & 107 & 17.58 \\
\hline 80 or more & 14 & 19 & 35.71 \\
\hline \multicolumn{4}{|c|}{ Gender of victim } \\
\hline Female & 516 & 682 & $32.17 * * *$ \\
\hline Male & 329 & 466 & $41.64 * * *$ \\
\hline Unknown & 101 & 93 & -7.92 \\
\hline \multicolumn{4}{|c|}{ Reporting channel } \\
\hline Telephone & 316 & 192 & $-39.24 * * *$ \\
\hline Website & 630 & 1,049 & $66.51 * * *$ \\
\hline \multicolumn{4}{|c|}{ Support requested to Action Fraud } \\
\hline Yes & 481 & 708 & $47.19 * * *$ \\
\hline No & 465 & 533 & $14.62^{*}$ \\
\hline \multicolumn{4}{|c|}{ Overall romance fraud } \\
\hline Crime reports & 946 & 1,241 & $31.18^{* * *}$ \\
\hline
\end{tabular}

*** p-value $<0.001 ; * * p$-value $<0.01 ; * p$-value $<0.05$

Table 1. Romance fraud known to Action Fraud in November and December 2019 and 2020

\subsection{Changes in internet use and loneliness}

Although results presented above show clear indicators that romance fraud increased during the pandemic, and such an increase was more evident among certain population groups than others, we also want to understand whether COVID provoked significant changes in people's loneliness and internet use (i.e., research question 3). This will provide valuable information to disentangle whether the increase in romance fraud can be somehow linked to changes in loneliness and internet use during COVID-19. It is important to note, however, that our method will not allow us to establish causal, or even correlational, associations between fraud victimisation suffered by individuals and changes in loneliness and internet use, but this information can be key to obtain preliminary insights that will be further addressed when newer sources of data about fraud victimisation and everyday activities become available. 
Since we have observed before that the change in romance fraud impacted different age groups differently, we have estimated our ARIMA models of loneliness and internet use by four age groups (i.e., 16 to 29,30 to 49, 50 to 69, and 70 or more). Results are shown in Figure 3, about changes in loneliness by age groups, and Figure 4, about changes in internet use. In both cases, the black line visualises the average monthly indicator across all respondents, and we visualise in colour the $95 \%$ prediction intervals computed from ARIMA modelling for both the pre-COVID and COVID periods.

In Figure 3, we can observe that the only age group that experienced significant changes in loneliness which fall outside the prediction intervals is the younger age group, those aged 16 to 29 . We see that the values of loneliness estimated in April and May 2020 are clearly above the upper prediction interval limit, and the score in November 2020 is also likely to fall outside the upper prediction interval limit. These two time periods (i.e., April and May 2020, and November 2020) coincide with some of the strictest lockdown restrictions seen in the UK, while during June, July and September some stayat-home orders were softened in most of the UK. While young respondents did experience an increase in loneliness, we do not find evidence of significant increases in loneliness experienced by middle-age respondents and older adults. Moreover, the average score of loneliness reported by older adults decreased after March 2020, compared to trends observed before COVID, but this change falls within the $95 \%$ prediction intervals and thus we cannot argue that it is a significant change.
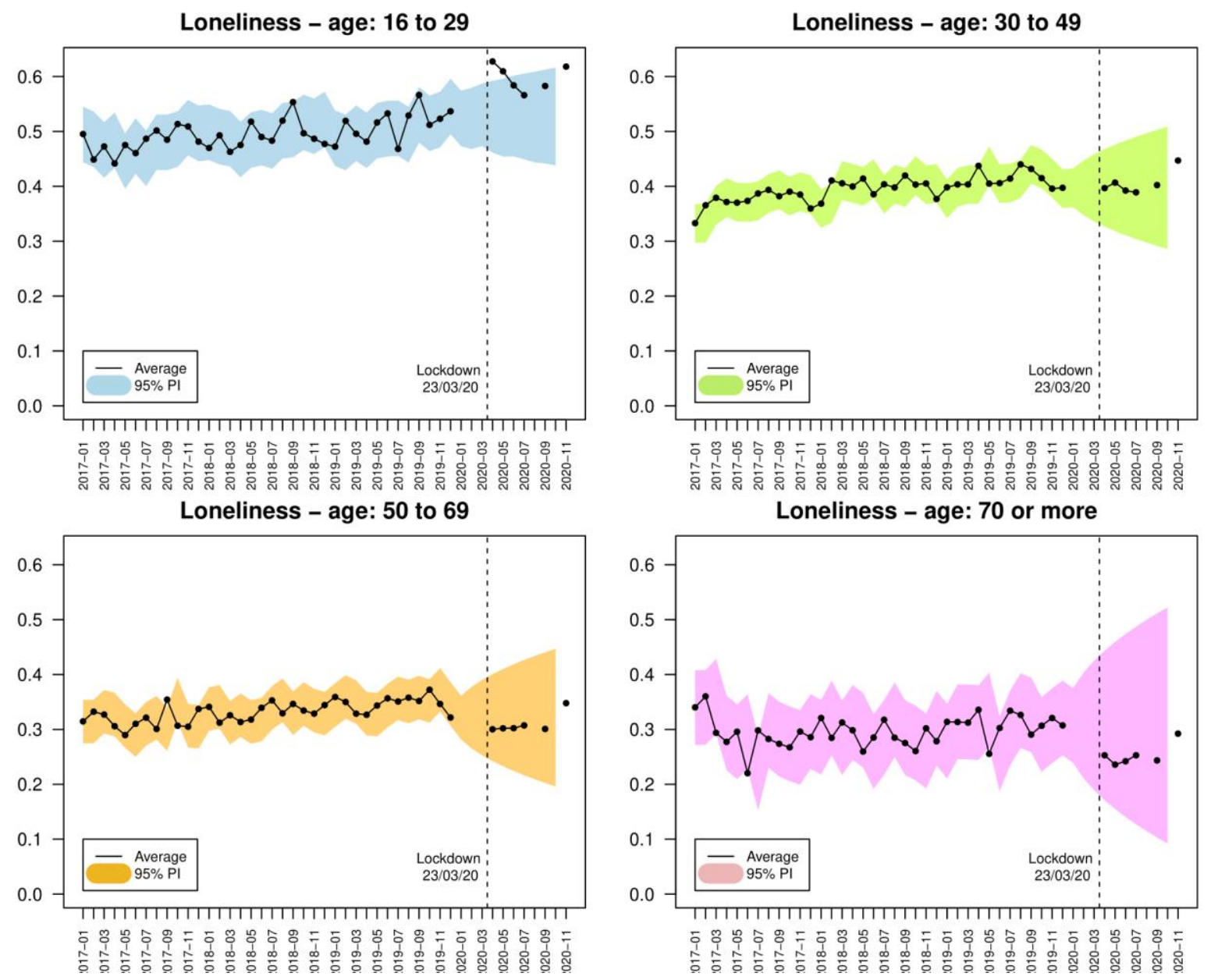

Figure 3. Proportion of respondents who feel lonely often or some of the time and 95\% prediction intervals

The trend of internet use across age groups, visualised in Figure 4, shows the opposite pattern, with older adults experiencing clear increases in internet use and younger respondents not reporting 
significant changes. While the proportion of young respondents who use the internet daily did not experience significant changes during COVID, those aged 50 or more, and especially the age group above 70, saw very large increases in daily internet use. In both groups (i.e., aged between 50 and 69, and 70 or older), the proportion of respondents who use the internet daily increased greatly above expected values forecasted from pre-COVID trends. We further discuss how changes in loneliness and internet use may have impacted romance fraud victimisation in Section 5.
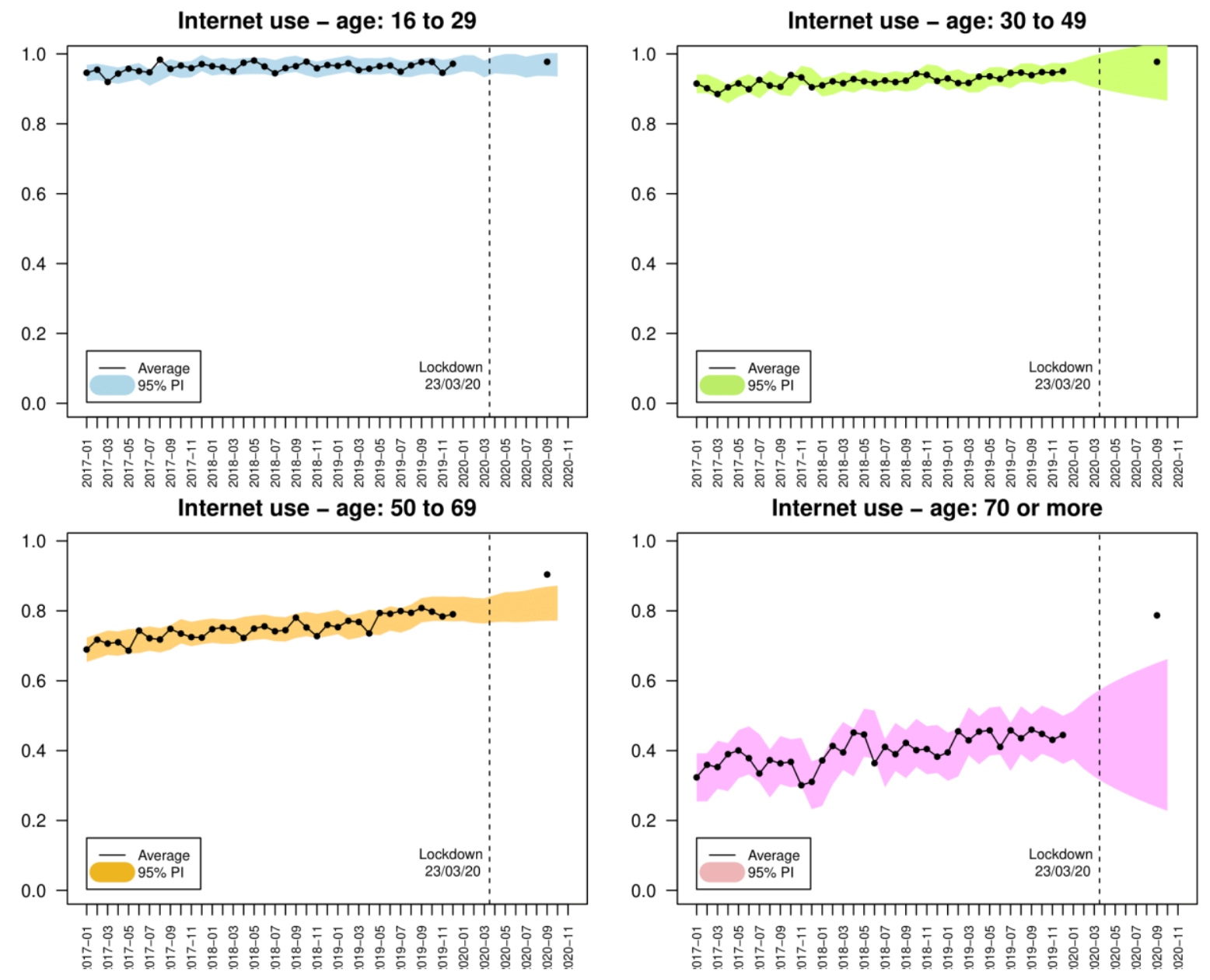

Figure 4. Proportion of respondents who use the internet daily and $95 \%$ prediction intervals

\section{Discussion and conclusions}

The coronavirus pandemic and the far-reaching lockdown and stay-at-home orders imposed by governments to control the spread of the virus had unintended consequences on various social domains affecting the everyday life of millions worldwide. COVID had clear effects on gender inequality (Czymara et al., 2020), education (Daniel, 2020), tourism (Sigala, 2020), and crime (Campedelli et al., 2020; Payne, 2020), among other social domains. While opportunities for many crime types decreased during COVID due to strict restrictions on social interaction (e.g., drug crime, street theft, residential burglary; Abrams, 2021; Langton et al., 2021), other crime types benefitted from it. Some clear examples of crimes that increased during COVID are domestic violence, since offenders and victims were confined together over long periods of time (Mohler et al., 2020; Piquero et al., 2020), and cybercrime and fraud, given the generalised increase in internet use for home working, online shopping, and leisure (Buil-Gil et al., 2020; Kemp et al., 2021). Based on Routine Activity Theory (Cohen and Felson, 1979), it is not surprising that the growth in internet use during 
COVID was associated with increased opportunities for a convergence between offenders and likely targets through online contexts. Moreover, some noted that in the context of cybercrime, offenders adapted their strategies to exploit some of the psychological effects of the pandemic, such as the worry about the virus and loneliness (Collier et al., 2020). It is likely, for instance, that fraudsters exploited the increase in online dating sites engagement (Chin and Robison, 2020; Goldstein and Flicker, 2020) and the potential increase in loneliness (Hwang et al., 2020; Li and Wang, 2020) to target a growing number of victims of romance fraud. In this paper we have analysed the extent to which romance fraud known to the police increased during COVID-19 in the UK, explored which population groups were the most affected by this type of fraud, and presented analyses about the increase in loneliness and internet use.

We have seen, first, that there was a clear and statistically significant increase in romance fraud after April 2020, and romance fraud rates remained high until December 2020. Such an increase remained well above the upper prediction interval limit computed from pre-COVID trends, showing that the growth in romance fraud cannot be explained by the upward trend seen before March 2020. It can be argued, thus, that the increase in romance fraud can be attributed to social changes seen during the pandemic. Moreover, we have also compared the count of crimes suffered by different population groups in November-December 2020 with the crime count recorded during same period in the previous year. Some population groups suffered a clearer increase in fraud victimisation than others. While all age groups experienced increases in the number of crimes recorded, such an increase was much more evident among young adults than older age groups, and the increase reported by adults aged 60 or more is not statistically significant. In order to further explore the extent of the increase in isolation and internet use during COVID, which some have pointed as important predictors of romance fraud (Cross, 2016; Kemp et al., 2021), we also conducted temporal analyses of these measures as recorded by the Understanding Society survey (Institute for Social and Economic Research, 2020). Our results indicate that young adults experienced a statistically significant increase in loneliness, while the increase in internet use was mainly seen by older adults. Li and Wang (2020) had already observed that young persons were at a higher risk of suffering loneliness during COVID-19, since their economic and social lives were more clearly disrupted by the pandemic. Regarding our finding that the increase in internet use affected mainly older adults, it is explained by the fact that younger adults were already making daily use of the internet before COVID, while many older persons began using the internet daily for online shopping, teleworking, and to communicate with family and friends during the first lockdown.

Methods used in this paper do not allow for inferences about the causal association between these observations, but it seems probable, if not highly likely, that the growth in romance fraud is due to a combined effect of the increases in loneliness and internet use seen during the pandemic. Younger adults experienced increasing levels of isolation during the pandemic, the proportion of adults using the internet daily grew, and as a consequence online dating sites reported record numbers in online engagement (Chin and Robison, 2020; Goldstein and Flicker, 2020). All these factors were likely exploited by fraudsters who, while adopting fake identities of 'ideal' partners, abused the trust of those who were suffering some of the psychological adverse effects of lockdown and social distancing policies. Suffering these frauds may have had severe financial and psychological effects on victims, including anxiety, stress, isolation, and depression (Carter, 2020; Cross et al., 2018), and our data show that around $60 \%$ of all victims requested additional support to the police.

Results presented here show that romance fraud is a growing crime in the UK, which not only increased drastically due to COVID restrictions, but also had been growing year after year for at least seven years. With the ever-growing increase in internet use, which has been favoured by the pandemic, 
a larger proportion of the population becomes potential victims of this crime type and other online frauds (Kemp et al., 2021). Moreover, we have seen how the increase in loneliness and isolation suffered by many, especially young adults, during the pandemic, may have fostered this type of crime and its harms among those who suffer it. While law enforcement agencies and policy makers should develop awareness campaigns to inform the public about the dangers of this crime, it is also important to establish and maintain cross-jurisdictional collaborations for crime investigation, establish partnerships with NGOs and education institutions to raise awareness across all population groups, and work collaboratively with online dating sites and social media to develop internal flagging systems and inform their users about romance fraud and its negative consequences.

While results presented here are first-of-its-kind and have important implications for research and policy, these are not free of limitations. First, our analysis of romance fraud is based on data about crimes known to the police. While police-recorded crime data is a valuable source of information and allows conducting a wide range of quantitative analyses on the effect of social changes on crime, these are affected by victims' underreporting and police forces' underrecording, which can be associated with problematic sources of measurement error. This is the reason why future research should use survey data to further understand the effect of COVID on fraud. Second, our research does not allow establishing causal associations between loneliness, internet use, and romance fraud, and further research should use survey microdata where possible. And third, our measure of loneliness is based on a single measure of frequency of loneliness feelings instead of the well-established 20-item UCLA scale of loneliness (Russell et al., 1978). Future research should use the UCLA scale to measure loneliness where possible. Moreover, future research may replicate this study in other countries, and analyse changes in romance fraud, loneliness, and internet use by the sex, ethnicity, and language skills of victims.

\section{Acknowledgements}

The authors would like to thank the City of London Police and UK Action Fraud for sharing the data used in this study.

\section{References}

Abrams, D.S. (2021), "COVID and crime: An early empirical look", Journal of Public Economics, Vol. 194. https://doi.org/10.1016/i.jpubeco.2020.104344

Action Fraud (2020), "Fall for the person, not the profile", available at: https://www.actionfraud.police.uk/campaign/fall-for-the-person-not-the-profile laccessed 13 February 2021)

Al-Saggaf, Y. and Nielsen, S. (2014), "Self-disclosure on Facebook among female users and its relationship to feelings of loneliness", Computers in Human Behavior, Vol. 36, pp.460-468. https://doi.org/10.1016/j.chb.2014.04.014

Buchanan, T. and Grant, A.J. (2001), "Investigating and prosecuting Nigerian fraud", United States Attorneys' Bulletin, Vol. 49, pp.39-48.

Buchanan, T. and Whitty, M.T. (2014), "The online dating romance scam: Causes and consequences of victimhood", Psychology, Crime \& Law, Vol. 20 No. 2, pp.261-283. https://doi.org/10.1080/1068316X.2013.772180 
Buil-Gil, D., Miró-Llinares, F., Moneva, A., Kemp, S. and Díaz-Castaño, N. (2020), “Cybercrime and shifts in opportunities during COVID-19: A preliminary analysis in the UK", European Societies. https://doi.org/10.1080/14616696.2020.1804973

Campedelli, G.M., Favarin, S., Aziani, A. and Piquero, A. R. (2020), "Disentangling community-level changes in crime trends during the COVID-19 pandemic in Chicago", Crime Science, Vol. 9. https://doi.org/10.1186/s40163-020-00131-8

Carter, E. (2020), "Distort, extort, deceive and exploit: Exploring the inner workings of a romance fraud", British Journal of Criminology. https://doi.org/10.1093/bjc/azaa072

Chin, C. and Robison, M. (2020), "This cuffing season, it's time to consider the privacy of dating apps", Brookings, available at: https://www.brookings.edu/blog/techtank/2020/11/20/this-cuffing-seasonits-time-to-consider-the-privacy-of-dating-apps/ (accessed 1 February 2021)

CIFAS (2020), "Romance Fraud: Fall for the person not the profile", available at: https://www.cifas.org.uk/insight/fraud-risk-focus-blog/romance-fraud-person-not-profile (accessed 13 February 2021)

Cohen, L.E. and Felson, M. (1979), "Social change and crime rate trends: a routine activity approach", American Sociological Review, Vol. 44 No. 4, pp.588-608. https://doi.org/10.2307/2094589

Collier, B., Horgan, S., Jones, R. and Shepherd, L. (2020), "The implications of the COVID-19 pandemic for cybercrime policing in Scotland: A rapid review of the evidence and future considerations", The Scottish Institute for Policing Research, Edinburgh, available at: https://rke.abertay.ac.uk/en/publications/the-implications-of-the-covid-19-pandemic-for-

cybercrime-policing (accessed 5 February 2021)

Cross, C. (2016), "They're very lonely': Understanding the fraud victimisation of seniors", International Journal for Crime, Justice and Social Democracy, Vol. 5 No. 4, pp.60-75. http://dx.doi.org/10.5204/iicisd.v5i4.268

Cross, C. (2020), "Theorising the impact of COVID-19 on the fraud victimisation of older persons", The Journal of Adult Protection. https://doi.org/10.1108/JAP-08-2020-0035

Cross, C., Dragiewicz, M. and Richards, K. (2018), "Understanding romance fraud: Insights from domestic violence research", British Journal of Criminology, Vol. 58 No. 6, pp.1303-1322. https://doi.org/10.1093/bic/azy005

Czymara, C.S., Langenkamp, A. and Cano, T. (2020), "Cause for concerns: Gender inequality in experiencing the COVID-19 lockdown in Germany", European Societies. https://doi.org/10.1080/14616696.2020.1808692

Daniel, S.J. (2020), "Education and the COVID-19 pandemic", Prospects, Vol. 49, pp.91-96. https://doi.org/10.1007/s11125-020-09464-3

Garside, R. (2020), "Covid: Romance fraudsters 'target lonely' in lockdown", BBC Wales News, available at: https://www.bbc.co.uk/news/uk-wales-54855321 (accessed 11 February 2021)

Goldstein, A. and Flicker, S. (2020), “'Some things just won't go back": Teen girls' online dating relationships during COVID-19", Girlhood Studies, Vol. 13 No. 3, pp.64-78. https://doi.org/10.3167/ghs.2020.130306 
Home Office (2020), "Home Office Counting Rules for Recorded Crime. Counting rules for fraud (with effect from April 2020)", GOV.UK, available at: https://assets.publishing.service.gov.uk/government/uploads/system/uploads/attachment data/file 881505/count-fraud-apr2-2020.pdf (accessed 20 January 2021)

Hwang, T., Rabheru, K., Peisah, C., Reichman, W. and Ikeda, M. (2020), "Loneliness and social isolation during the COVID-19 pandemic", International Psychogeriatrics, Vol. 32 No. 10, pp.1217-1220. https://doi.org/10.1017/S1041610220000988

Hyndman, R.J. and Athanasopoulos, G. (2018), Forecasting: Principles and practice (Second edition), OTEXTS, Malbourne.

Hyndman, R.J., and Khandakar, Y. (2008), "Automatic time series forecasting: The forecast package for R", Journal of Statistical Software, Vol. 27 No. 1, pp.1-22. https://doi.org/10.18637/jss.v027.i03

Institute for Social and Economic Research (2020), Understanding Society: Waves 1-10, 2009-2019 and Harmonised BHPS: Waves 1-18, 1991-2009, UK Data Service (distributor), available at: http://doi.org/10.5255/UKDA-SN-6614-14 (accessed 11 January 2021)

Institute for Social and Economic Research (2021), Understanding Society: COVID-19 Study, 2020, UK Data Service (distributor), available at: http://doi.org/10.5255/UKDA-SN-8644-7 (accessed 11 January 2021)

Kemp, S., Buil-Gil, D., Moneva, A., Miró-Llinares, F. and Díaz-Castaño, N. (2021), "Empty streets, busy internet. A time series analysis of cybercrime and fraud trends during COVID-19", Journal of Contemporary Criminal Justice.

Killgore, W.D.S., Cloonan, S.A., Taylor, E.C. and Dailey, N.S. (2020), "Loneliness: A signature mental health concern in the era of COVID-19", Psychiatry Research, Vol. 290, pp.113117. https://doi.org/10.1016/i.psychres.2020.113117

Király, O., Potenza, M.N., Stein, D.J., King, D.L., Hodgins, D.C., Saunders, J.B., Griffiths, M.D., Gjoneska, B., Billieux, J., Brand, M., Abbott, M.W., Chamberlain, S.R., Corazza, O., Burkauskas, J., Sales, C.M.D., Montag, C., Lochner, C., Grünblatt, E., Wegmann, E., Martinotti, G., Lee, H.K., Rumpf, H., Castro-Calvo, J., Rahimi-Movaghar, A., Higuchi, S., Menchon, J.M., Zohar, J., Pellegrini, L., Walitza, S., Fineberg, N.A. and Demetrovics, Z. (2020), "Preventing problematic internet use during the COVID-19 pandemic: Consensus guidance", Comprehensive Psychiatry, Vol. 100, pp.152180. https://doi.org/10.1016/j.comppsych.2020.152180

Langton, S., Dixon, A. and Farrell, G. (2021), "Six months in: Pandemic crime trends in England and Wales", Crime Science.

Lawson, H.E. and Leck, K. (2006), "Dynamics of Internet dating", Social Science Computer Review, Vol. 24 No. 2, pp.189-208. https://doi.org/10.1177/0894439305283402

Li, L.Z. and Wang, S. (2020), "Prevalence and predictors of general psychiatric disorders and loneliness during COVID-19 in the United Kingdom", Psychiatry Research, Vol. 291, pp.113267. https://doi.org/10.1016/j.psychres.2020.113267

Loades, M.E., Chatburn, E., Higson-Sweeney, N., Reynolds, S., Shafran, R., Brigden, A., Linney, C., McManus, M.N., Borwick, C. and Crawley, E. (2020), "Rapid systematic review: The impact of social isolation and loneliness on the mental health of children and adolescents in the context of COVID-19", 
Journal of the American Academy of Child \& Adolescent Psychiatry, Vol. 59 No. 11, pp.1218-1239. https://doi.org/10.1016/j.jaac.2020.05.009

Mohler, G., Bertozzi, A.L., Carter, J., Short, M.B., Sledge, D., Tita, G.E., Uchida, C.D. and Brantingham, P.J. (2020), "Impact of social distancing during COVID-19 pandemic on crime in Los Angeles and Indianapolis", Journal of Criminal Justice, Vol. 68. https://doi.org/10.1016/j.jcrimjus.2020.101692

Payne, B.K. (2020), "Criminals work from home during pandemics too: A public health approach to respond to fraud and crimes against those 50 and above", American Journal of Criminal Justice, Vol. 45, pp.563-577. https://doi.org/10.1007/s12103-020-09532-6

Piquero, A.R., Riddell, J.R., Bishopp, S.A., Narvey, C., Reid, J.A. and Piquero, N.L. (2020), "Staying home, staying safe? A short-term analysis of COVID-19 on Dallas domestic violence", American Journal of Criminal Justice, Vol. 45, pp.601-635. https://doi.org/10.1007/s12103-020-09531-7

R Core Team (2020), R: A language and environment for statistical computing, R Foundation for Statistical Computing, Vienna, Austria, available at: https://www.r-project.org/ (accessed 27 December 2020)

Russell, D., Peplau, L.A. and Ferguson, M.L. (1978), "Developing a measure of loneliness", Journal of Personality Assessment, Vol. 42 No. 3, pp.290-294. https://doi.org/10.1207/s15327752ipa4203 11

Sigala, M. (2020), "Tourism and COVID-19: Impacts and implications for advancing and resetting industry and research", Journal of Business Research, Vol. 117, pp.312-321. https://doi.org/10.1016/j.jbusres.2020.06.015

Whitty, M.T. (2013), "The scammers persuasive techniques model: Development of a stage model to explain the online dating romance scam", British Journal of Criminology, Vol. 53 No. 4, pp.665-684. https://doi.org/10.1093/bjc/azt009

Whitty, M.T. (2018), "Do you love me? Psychological characteristics of romance scam victims", Cyberpsychology, Behavior, and Social Networking, Vol. 21 No. 2, pp.105-109. https://doi.org/10.1089/cyber.2016.0729 